\title{
Problems and Countermeasures in the Reform of College Physical Education
}

\author{
Song Haiquan, Chen Hui \\ Guangzhou Huali Science and Technology Vocational College, Guangzhou, China, 511325
}

Keywords: college physical education; deepening reform; problem; countermeasure

Abstract: China has carried out many years of reforms in college physical education classrooms and has made tremendous achievements. However, in the new historical starting point of deepening reform, they are faced with many problems and challenges. They directly or indirectly affect the process of college physical education reform, and even become an obstacle on the road to reform. It is urgent to solve these problems in time and remove the obstacles in the reform. Based on the background of current physical education teaching reform in colleges and universities in China, this paper divides the existing problems and solutions of physical education teaching reform in colleges and universities so as to build physical education courses into a platform for students to take the initiative to exercise, develop the habit of physical exercise and build a healthy and excellent body.

\section{Introduction}

Physical education plays an important role in China's higher education system. Its reform has also received much attention. Under the new situation, quality education is being promoted extensively and comprehensively. Obviously, we must make reforms and innovations in the traditional physical education model to adapt to the new environment. Only in this way can we better adapt to the teaching needs of the new era, and can cultivate sports talents that meet the requirements of the new era and lay a talent foundation for China's socialist construction ${ }^{[1]}$.

\section{The background and guiding ideology of physical education reform in colleges and universities}

As early as 1995, China promulgated and implemented the "National Fitness Program Outline", calling on people to "strengthen physical fitness training" can be said to be an important strategic plan for sports development in the 21st century, and its target of course also includes student groups. At present, colleges and universities in China bear the important responsibility of cultivating students' awareness of physical exercise, improving students' exercise skills and establishing good fitness habits. The reform of college physical education is based on this. In addition, in the process of college physical education reform, we should always adhere to two ideas: First, hold high the banner of quality education. Physical education reform is an important part of the development of quality education. It is of great significance to the overall development of students. Therefore, the 
current college physical education reform should be based on quality education and highlight the idea of "health first". The second is to promote the idea of lifelong sports. Lifelong sports is developed from the connotation of lifelong education. It is understandable that our college physical education is in line with the requirement of lifelong education. It is necessary to advocate and establish lifelong sports ${ }^{[2]}$.

\section{The main problems currently existing in the reform of college physical education}

\subsection{Theoretical research and teaching practice lack interactivity}

After the implementation of "sports sports", "quality education", "happy sports", and other educational concepts, the reform of physical education in colleges and universities has broadened the educational level, which has greatly enriched the content of physical education in colleges and universities. However, the practice of college physical education reform lacks a sense of unity and is not complete in the form of research. At present, China's traditional teaching system and theoretical model are still not replaced by perfect systems and models. It is still the use of sports technology as the center, but only from the three-chip one-sided reinforcement of load intensity to stimulate students' physique, these traditional teaching concepts still not broken.

\subsection{More physical education content than fine}

Although the content of teaching is varied, it all achieves inaccuracy. In the physical education of colleges and universities, some simple physical education courses are too messy. College students in colleges and universities are different from primary and secondary school students. They are no longer childish and blind, but they have begun to accept and control. Therefore, to train students in colleges and universities, it should be mainly in the two aspects of conservation and management. If the current physical education teaching in China is not improved, it will inevitably affect the students' interest in learning, and the mentality of learning is only due to coping, so it does not conform to the law of the formation of sports technology. In the end, although there are compulsory courses for many years, there are no projects that are of interest to them, and their long-term items cannot be effectively played $^{[3]}$.

\subsection{The evaluation method is relatively simple, and the assessment system is imperfect}

The evaluation of physical education in colleges and universities still evaluates the students' performance according to the traditional level of physical education technology. The single simple means of investigation is too absolute, and it does not clearly reflect the students' learning level and performance. At the same time, some colleges and universities do not pay attention to the teaching of physical education. In the process of physical examination and physical fitness test, it is easy to appear the test, the test, and the false report. This is a violation of national policies. It is not a disrespect for physical education and is also irresponsible for the health of students. Table 1 is a survey of the purpose of college students to participate in physical exercise.

Table 1 The purpose of college students to participate in physical exercise

\begin{tabular}{|c|c|c|}
\hline Purpose & Number of people & Percentage(\%) \\
\hline Strong fitness & 609 & 69.6 \\
\hline Coping with exam needs & 92 & 10.5 \\
\hline kill time & 57 & 6.5 \\
\hline Other needs & 62 & 7.1 \\
\hline No purpose & 55 & 6.3 \\
\hline
\end{tabular}




\section{Countermeasures for the teaching reform of physical education curriculum in colleges and universities}

\subsection{Clarify the goal of physical education and scientifically set up physical education courses}

Physical education is of vital importance and deserves the dual attention of educators and educators. Physical education in colleges and universities should be based on the method of attracting students with interest, with the aim of cultivating lifelong sports awareness, and aiming at the country to train healthy and qualified successors. At the same time, to set up physical education courses scientifically, students' physical education should be comprehensive, not individual. Sports theory knowledge is the basis of skill knowledge. Should follow the sequence, reasonably arrange the class hours, use the theory to guide the skills, let the students calm down to learn in the teacher, but also let the school life splash up to train skills in the playground. In this way, students can be taught more comprehensive sports knowledge, so as to mobilize the enthusiasm of students to learn and exercise, and then cultivate students' habits of voluntary lifelong sports, so that students can benefit from the new physical education mode for life ${ }^{[4]}$.

\subsection{Reasonably improve teaching content and comprehensively innovate teaching methods}

The improvement of teaching content is an important task of the relevant departments of colleges and universities. The relevant content of physical education should be rationally and scientifically improved in combination with the faculty strength of the university, the overall quality of the students and the corresponding teaching objectives. At the same time, we must not neglect the students' personal hobbies, and strive to show the concept of students as the main body, so that it can be more targeted and operability, which can be more conducive to improving the enthusiasm of students' sports learning.

In physical education, our teachers cannot blindly abandon traditional teaching methods. For the traditional teaching methods, we should further improve and innovate on the basis of respect and reference. We must pay more attention to cultivating students' interest and hobbies in sports. They should not be too rigid, but should flexibly adapt various means. In combination with the current people's physical exercise goals and mainstream, carry out training activities suitable for students' physical fitness. Figure 1 is a new approach to the reform of college physical education ${ }^{[5]}$.

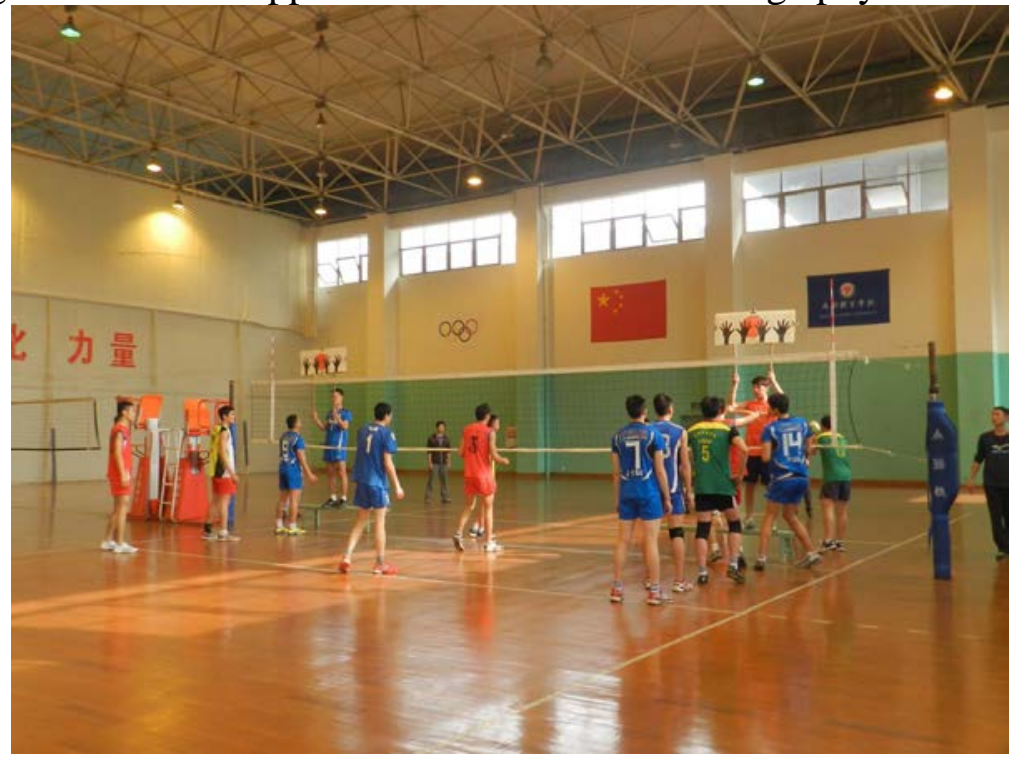

Figure 1 College sports innovative teaching method 


\subsection{Establish a scientific evaluation system}

The establishment of a scientific evaluation system is indispensable in the reform of physical education, and its establishment can help achieve higher curriculum goals. The establishment of our physical education curriculum evaluation system needs to adhere to the "people-oriented" spirit, not only pay attention to the final results, but also pay attention to the improvement of relevant capabilities in the whole process. Of course, this does not completely negate the meaning of traditional physical education evaluation. It just believes that a scientific evaluation system cannot lack or neglect the progress of individual students in the process of physical education and the creativity they display. Therefore, establish a scientific evaluation system for physical education. The first evaluation runs through the entire physical education process and can be carried out through student self-evaluation, mutual evaluation, and teacher-student evaluation. Second, teachers should pay attention to each kind of progress of students, pay attention to their detailed growth in learning attitudes, innovative spirits, etc., and stimulate students to continuously improve themselves.

\section{Conclusions}

All in all, our college physical education teaching is based on enhancing students' physical fitness and promoting students' physical and mental health. The reform of physical education in colleges and universities can only implement the guiding ideology of lifelong physical education, take quality education as the guide, adhere to the principle of "health first", and cultivate students' awareness of lifelong training, so that students can enjoy the comprehensive and balanced development of morality, intelligence, body and beauty. At the same time, for the reform, it is necessary to constantly identify and solve problems, keep pace with The Times, explore and innovate, and avoid one-sidedness. Only in this way can our university physical education make continuous progress in practice and constantly promote the development of physical education reform.

\section{References}

[1] Wang Dongliang. Problems and Countermeasures in the Reform of College Physical Education Teaching [J]. Journal of Changchun Institute of Education, 2013, 29(19): 116-117.

[2] Du Jiangwei. Analysis on the Problems and Countermeasures in the Reform of College Physical Education Teaching [J]. Journal of Wuyi University, 2013, 32(5): 79-82.

[3] Zhang Rong. Discussion on the Problems and Countermeasures in the Reform of Physical Education Teaching in Colleges and Universities in China [J]. Culture \& Sports Products \& Technology, 2015(10):56-57.

[4] Yin Yingjie, Li Hui. Exploration and Practice of Deep Integration Model of Higher Vocational Education in Production and Education [J]. Journal of Shijiazhuang Railway Vocational and Technical College, 2015, 14(2): 108-112.

[5] Zhang Shouzhong. Problems and Countermeasures in the Process of Deepening the Reform of Physical Education in Colleges and Universities [J]. Heilongjiang Higher Education Research, 2015(8): 52-55. 